\title{
МУЛЬТИДЕСКРИПТОРНОЕ НЕЙРОСЕТЕВОЕ МОДЕЛИРОВАНИЕ ТҮК2-ИНГИБИРУЮЩЕЙ АКТИВНОСТИ ХИМИЧЕСКИХ СОЕДИНЕНИЙ
}

\author{
А.Р. Королева', П.М. Васильев ${ }^{1,2}$, Д.А. Бабков ${ }^{1,2}$, А.Н. Кочетков \\ ${ }^{1}$ Кафедра фармакологии и биоинформатики, ФГБОУ ВО ВолгГМУ \\ Минздрава России, 400001, Россия, г. Волгоград, ул. Ким, д. 20. \\ ${ }^{2}$ Научный центр инновационных лекарственных средств, ФГБОУ ВО ВолгГМУ Минздрава \\ России, 400087, Россия, г. Волгоград, ул. Новороссийская, 39.
}

DOI: 10.19163/MedChemRussia2021-2021-182

E-mail: korolyova1698@mail.ru

Целью исследования явилось построение на основе технологии многослойных перцептронных нейронных сетей модели зависимости уровня TYК2-ингибирующей активности химических соединений от их множественного описания структурными дескрипторами.

Создана верифицированная база данных структур и активности 2156 известных ингибиторов нерецепторной тирозин-протеинкиназы 2 (TYK2). Градации уровней активности определяли путем объединения сходных методик и последующей кластеризации. С применением системы IT Microcosm v7.3 для этих соединений было получено описание их структуры в виде множества дескрипторов первого ранга языка QL. C использованием технологии искусственных нейронных сетей прямого распространения с архитектурой многослойного перцептрона рассчитаны зависимости для прогноза высокого и выраженного уровней TYК2-ингибирующей активности. Обучение проводили в программе Statistica в стандартном режиме. Для каждого уровня активности было построено по 200 нейронных сетей, среди которых, по оценкам точности прогноза на объединенной выборке и данным ROC-анализа, выбрана наилучшая сеть.

Найдены оптимальные нейросетевые модели со следующими характеристиками прогностической способности: общая точность $F_{0}=90,7 \%$, чувствительность $\mathrm{F}_{\mathrm{a}}=85,3 \%$, специфичность $\mathrm{F}_{\mathrm{n}}=93,5 \%$, площадь под кривой $A U C_{R O C}=95,2 \% ; F_{0}=9, .6 \%, F_{a}=93,9 \%, F_{n}=90,7 \%, A U C_{\text {ROC }}=96,5 \%$ - для высокого и выраженного уровней ТYК2-ингибирующей активности соответственно.

На основе технологии многослойных перцептронных нейронных сетей построены модели зависимости уровня ТYК2-ингибирующей активности химических соединений от их множественного описания структурными дескрипторами. Модели используются для поиска новых соединений, предотвращающих развитие цитокинового шторма при COVID-19.

Работа выполнена при финансовой поддержке гранта Минобрнауки РФ № 075-15-20-777. 